\title{
Association of Alpha-2 Beta-1 Integrin Polymorphism with Retinopathy in Diabetic Patients
}

Nadeem Afzal' ${ }^{1 *}$, Nagi AH ${ }^{2}$, Muhammad Imran ${ }^{3}$, Abu Zafar ${ }^{4}$, Amtul Musawar $^{5}$, Romeeza Tahir ${ }^{1}$, Sarwar Abbas $^{1}$, Afia Abbas $^{1}$, Shakeela Zaman $^{6}$ and Shah Jahan

${ }^{1}$ Department of Immunology, University of Health Sciences, Lahore, Pakistan

${ }^{2}$ Department of Pathology, University of Health Sciences, Lahore, Pakistan

${ }^{3}$ Centre for Research in Endocrinology and Reproductive Sciences, Department of Physiology and Cell Biology, University of Health Sciences, Pakistan

${ }^{4}$ Amin Hayat Memorial Diabetic Centre, Lahore, Pakistan

${ }^{5}$ Services Hospital, Lahore, Pakistan

${ }^{6}$ Children Hospital and Institute of Child Health, Lahore, Pakistan

\begin{abstract}
Aim: Diabetes mellitus (DM) is a health concern because it leads to complications such as retinopathy and nephropathy. Pakistan has 6.9 million DM affected people that will be doubled by 2025. A study was designed to determine the role of genetics in diabetic retinopathy in Pakistani type 2 diabetes mellitus (T2DM) patients.

Material and methods: It was a cross-sectional case-control study that included 236 subjects, divided into Group I (54 volunteers without diabetes), Group II (30 T2DM patients without retinopathy) and Group III (152 T2DM patients with retinopathy). A Bg/ll polymorphism of $\alpha 2 \beta 1$ integrin gene was genotyped in all these individuals by using RFLP method.
\end{abstract}

Results: The frequency of Bg/ll polymorphism (++ and +-) genotypes was found significantly different between group I and group III individuals.

Conclusion: $B g / l l(+/+,+/-)$ genotypes, gender of subject, age at the onset of diabetes, and duration of diabetes is associated with development of diabetic retinopathy in Pakistani T2DM patients.

Keywords: Diabetes mellitus; DNA; Polymorphism; PCR; RFLP

\section{Introduction}

Diabetes mellitus has increased significant burden on human health because it leads to numerous and serious complications such as retinopathy, nephropathy, and cardiovascular diseases. There are many risk factors that are associated with diabetes and its complications such as diet, sedentary life-style, age, obesity and genetic profile of a person [1]. According to W.H.O. 1999 [2], diagnosis of diabetes should consist of both fasting and 2 hour post $(75 \mathrm{~g})$ glucose load. Type 2 Diabetes mellitus (T2DM) is one of the leading causes of morbidity and mortality in the world. It is estimated that this disease affects 240 million people worldwide and this number would be increased to 380 million by 2025 , with the $80 \%$ of burden in low and middle income countries [3]. In the United States of America, the prevalence of diabetes was estimated as $13.7 \%$ and $11.7 \%$ among men and women of $\geq 30$ years of age, respectively, while it is the sixth leading cause of death in the US [4]. Even if, the prevalence of obesity remains stable, until 2030 the number of diabetes patients will be more than double as a consequence of population aging and urbanization [5]. Regarding diabetes, Pakistan belongs to high prevalence area, currently have 6.9 million affected people that will be doubled by 2025 and it may affect 11.5 million people [3].

T2DM is more common and it occurs mainly in adults but now it is being recognized as epidemic of young. This disease is affecting all age groups, and children of 8 years or even younger have been reported with this disease. The reason for rise in childhood and adolescent T2DM is linked with obesity which is associated with changes in dietary and lifestyle patterns. Japan and Taiwan are recording more childhood cases of T2DM than type-1 diabetes, similarly in the USA; T2DM is catching up with type- 1 diabetes. In 20 years T2DM may account for $60 \%$ of the disease burden and mortality in the developing world $[6,7]$.
There is a strong family history among affected youth with $45 \%-80 \%$ having at least one parent with diabetes and $74 \%-100 \%$ having first or second degree relative with T2DM [6].

The rate of being overweight and obese is low in Asians as compared to Western people but Asian countries have higher prevalence of diabetes than western countries. Childhood obesity, abdominal obesity, low muscle mass with increased insulin resistance, and even at low BMI put Asians at high risk for T2DM in early adulthood compared to Western [8]. Prolonged hyperglycaemia causes alteration in retinal and renal blood flow, metabolic changes and no enzymatic glycosylation of long-lived tissue proteins. This leads to vascular dysfunction in microcirculation and contribute towards diabetic retinopathy and nephropathy [9].

Diabetic retinopathy (DR) is a horrifying prospect [1] of diabetes. It is the leading cause of blindness under 65 years of age in the United States and a major cause of vision loss in the developing world [10]. Its risk would be doubled in next 30 years [8]. It is characterized by increased vascular permeability, tissue ischemia and neoangiogenesis [11]. Blood vessels are low in retina and inner retina has a few

${ }^{*}$ Corresponding author: Nadeem Afzal, Associate Professor, Head, Departmen of Immunology, University of Health Sciences, Lahore, Pakistan, Tel: 92-321-4086452; Fax: 92-42-99230870; E-mail: immunology@uhs.edu.pk, ndmfzl@yahoo.com

Received September 25, 2012; Accepted October 25, 2012; Published October 30, 2012

Citation: Afzal N, Nagi AH, Imran M, Zafar A, Musawar A, et al. (2012) Association of Alpha-2 Beta-1 Integrin Polymorphism with Retinopathy in Diabetic Patients. J Diabetes Metab 3: 223. doi:10.4172/2155-6156.1000223

Copyright: ( 2012 Afzal N, et al. This is an open-access article distributed unde the terms of the Creative Commons Attribution License, which permits unrestricted use, distribution, and reproduction in any medium, provided the original author and source are credited. 
mitochondria containing enzymes for oxidative phosphorylation compared to the outer side of retina where oxygen supply is comparatively more $[7,11,12]$.

Genetic factors [9], environmental factors along with low birth weight and gestational diabetes are the main reasons for the high prevalence of T2DM in Pakistan [13]. Since gene expression varies in different environmental conditions; therefore, not all diabetics develop DR. The risk of developing severe DR increases in the siblings of affected individuals. The frequency of DR varies with ethnicity and race. Many genes have been studied to determine an association with DR [14]

Over 30 genes have been studied for an association with DR, however, only a fraction of them has shown consistent associations: Aldose reductase (AR2) gene polymorphism, endothelial nitric oxide synthase (eNOS), lymphotoxin-a (LTA), angiotensin converting enzyme (ACE), vascular endothelial growth factor (VEGF), intracellular adhesion molecule 1 (ICAM-1 or CD45), $\beta 3$-adrenergic receptor gene (ADRB3), endothelin-1 (EDN1) [15], advanced glycation end products receptor, haemochromatosis, and alpha2 beta1 integrin [16].

Integrin $\alpha 2 \beta 1$ is a glycoprotein which acts as a receptor for collagen present on the membranes of platelets. Therefore, platelet glycoprotein (GP) plays a vital role in platelet adhesion and aggregation, for the development of thrombosis and hemostasis. Variation in platelet GP density becomes a risk factor for haemostatic abnormalities [17] and this platelet $\alpha 2 \beta 1$ density is genetically determined [18]. Hereditary variation in platelet level of $\alpha 2 \beta 1$ integrin is defined by the existence of multiple alleles of $\alpha 2$ gene therefore it could have a significant impact on platelet function, contributing to an increased risk of thrombosis or bleeding in relevant disease states [19]. The same polymorphism has been studied by Matsubara et al. [20] and Shi et al. [21] in Japanese and Suzhou Han population respectively. Polymorphism in introns-7 of $\alpha$ subunit of collagen receptor encoded by $\alpha 2 \beta 1$ gene makes retina vulnerable during hyperglycaemia [22].

BglII polymorphism of a subunit of $\alpha 2 \beta 1$ integrin has been associated with the extent of platelet adhesion to collagen and DR in Japanese population. The BglII (+) containing platelets can easily interact with non-enzymatically glycosylated collagen and accelerate the process of retinopathy. BglII $(+/+,+/-)$ genotypes increased the risk of retinopathy and nephropathy [22]. A higher frequency of $B g l \mathrm{II}(+/+)$ genotype of gene polymorphism of $\alpha 2 \beta 1$ integrin gene was found in Caucasians T2DM with DR compared with patients without DR. In addition to BglII $(+/+)$ polymorphism, age of onset diabetes, duration of diabetes, and insulin therapy were independent risk factor for DR [18] whereas Tsai et al. [23] could not determine an association with DR in the Chinese population with T2DM. A BglII polymorphism has also been detected within prolactin gene region [24].

Diabetic patients with BglII polymorphism (+/-, +/+) develop DR and nephropathy which indicates involvement of platelets, therefore these patients may get benefit from anti-platelet therapy [22]. The precise mechanisms involved in aetiopathogenesis of DR are not known [25] therefore better means for identification, prevention and treatment of DR should be developed before the onset of vision loss [1]. Further studies are required for the analysis of these genes in order to have better understanding of pathophysiology of diabetes [12]. Therefore; a study was designed to evaluate the role of genetic variation in DR. In this study, association of $\alpha 2 \beta 1$ Integrin gene polymorphism with DR has been determined.

\section{Material and Methods}

\section{Sample collection}

In this cross-sectional case-control study, 236 unrelated subjects between 20-75 years were enrolled. Among these subjects, 152 patients had type 2 diabetes mellitus and retinopathy while 30 subjects had T2DM and they did not have retinopathy. Diabetic patients had a history of diabetes for the last 5 years and maximum duration of diabetes was 25 years. In this study, 54 healthy volunteers were included who did not have diabetes mellitus. Patients of T2DM were diagnosed according to World Health Organization criteria (WHO 1999) [2]. Subjects with a history of infection in the last two weeks and suffering from chronic infections like $\mathrm{TB}$, autoimmune disorders, etc. were excluded. Further, to avoid confounding effect of impaired kidney function, patients with obvious nephropathy were not enrolled in the study. The study was approved by the Advanced Study and Research Board and Ethical Committee of the University. Study subjects were recruited from Amin-Hayat Memorial Center for diabetes, Mughal Eye Hospital, Services Hospital and Sheikh Zayed Hospital, Lahore. At each of these centers, diagnosis of retinopathy was made by the consultant ophthalmologist. After explaining details of the study, written informed consent from each participant was obtained.

\section{DNA extraction}

Five $\mathrm{ml}$ of blood was collected in a sterile vacutainer containing EDTA as anti-coagulant and it was stored at $-20^{\circ} \mathrm{C}$ for 24 hours. In each aliquot, $500 \mu$ l of whole blood was mixed with $700 \mu \mathrm{l}$ of TE buffer, centrifuged at $13500 \mathrm{rpm}$ for 10 minutes. Supernatant was discarded and pallet at the bottom of each aliquot was broken and $700 \mu \mathrm{l}$ of TE buffer was added. It was centrifuged again at $13500 \mathrm{rpm}$ for 10 minutes. Washing steps were repeated for 3-4 times to get white pellet, Then DNA was extracted after RBC washing by standard protocol as reported earlier [26]. Extracted DNA was quantified by spectrophotometer and was confirmed by Gel Electrophoresis.

\section{Genotyping of BglII polymorphism}

For genotyping of BglII polymorphism, restriction fragment length polymorphism (RFLP) technique was used. In this method, a $600 \mathrm{bp}$ DNA fragment that contains BglII site that is located in intron 7 was amplified by PCR with a thermal cycler (BioRad). For PCR, we used DNA $=1 \mu \mathrm{l}$, DNTPs $=2 \mu \mathrm{l}$, Primer $1=1 \mu \mathrm{l}$, Primer $2=1 \mu \mathrm{l}$ (as described by Matsubara et al. [20], Taq $=0.2 \mu \mathrm{l}$, buffer $(\mathrm{NH} 4)_{2} \mathrm{SO}_{4}=2.5 \mu \mathrm{l}, \mathrm{MgCl}_{2}=3$ $\mu \mathrm{l}$, and $\mathrm{dH}_{2} \mathrm{O}=14.3 \mu \mathrm{l}$. The setting for the run of mixture for PCR was $95^{\circ} \mathrm{C} 4 \mathrm{~min}, 94^{\circ} \mathrm{C} 30 \mathrm{sec}, 59^{\circ} \mathrm{C} 30 \mathrm{sec}, 72^{\circ} \mathrm{C} 1 \mathrm{~min}, 72^{\circ} \mathrm{C} 10 \mathrm{~min}, 40^{\circ} \mathrm{C}$ and the number of cycles were 35 . Sequences of primers are given in table 1. Amplified DNA was digested with $B g l I I$ at $37^{\circ} \mathrm{C}$ for 3 hours. Resulting product was electrophoresed on $2 \%$ agarose gel. The PCR products containing BglII (+) was cut into fragments of $200 \mathrm{bp}$ and 400 bp whereas those containing BglII(-) were not cut (Figure 1).

\section{Statistical analysis}

Data was analysed using SPSS 17.0, Mean + SD, frequencies and percentages were used for qualitative variables. Tables and figure are presented for both qualitative and quantitative variables. One way ANOVA to observe group mean differences, Post Hoc Tukey test to observe group means differs, Pearson correlation test to observe correlation between quantitative variables and Pearson Chi-Square test was applied to observe associations between qualitative variables. A $p$ value of $\leq 0.05$ was considered statistically significant. 
Citation: Afzal N, Nagi AH, Imran M, Zafar A, Musawar A, et al. (2012) Association of Alpha-2 Beta-1 Integrin Polymorphism with Retinopathy in Diabetic Patients. J Diabetes Metab 3: 223. doi:10.4172/2155-6156.1000223

Page 3 of 5

\section{Results}

The Group I included 34 (63\%) males and 20 (37\%) females, Group II had $5(16.66 \%)$ males and $25(83.33 \%)$ females and Group III included $51(33.55 \%)$ males and $101(66.44 \%)$ females. The demographic data such as age range, gender distribution, level of HbAlc, and duration of diabetes of the subjects enrolled in this study is given in table 1 . The distribution of frequency of $B g l I I$ polymorphism in all the three groups is shown in table 2 .

The frequency of BglII polymorphism i.e. disease associated homozygous positive $(++)$, disease associated heterozygous positive $(+-)$ and non-disease associated homozygous negative (--) for the allele of $\alpha 2 \beta 1$ integrin gene was determined in all the studied population.

In Group I, 3 (5.55\%) subjects had ++ polymorphism, there were $33(61.11 \%)$ subjects with +- polymorphism and $18(33.33 \%)$ subjects had -- polymorphism. In Group II, there were 4 (13.3\%) subjects who had ++ polymorphism, $16(53.3 \%)$ subjects had +- polymorphism and $10(33.33 \%)$ subjects had -- polymorphism. In Group III, 29 (19.1\%) subjects had ++ polymorphism, 67 (44.7\%) subjects had +polymorphism and $56(36.84 \%)$ subjects had -- polymorphism. In total, $33(15.25 \%)$ subjects had ++ polymorphism, $116(49.15 \%)$ had +- polymorphism and 84 (33.59\%) had -- polymorphism.

On comparison of Bgl II polymorphism between Group I and Group III, higher percentage of ++ polymorphism was found in Group III (29\%) compared to Group I (3\%) ( $p$ value=0.027).

BglII polymorphism (+/+, +/-, -/-) genotypes were compared for association analysis by using all three models i.e. codominant, dominant and recessive model. On comparison, Group I and Group III showed statistically significant value in codominant and recessive models. Association of BglII genotypes was non-significant when Group I was compared with Group II and Group II was compared with Group III. The details are given in table 3.

The dose of BglII alleles was compared to determine the influence of these alleles on the development of DR. The detail of alleles' comparison is given in table 4 .

\section{Discussion}

Various epidemiological and experimental studies show that disease duration of diabetes and glycemic control is major determinants for the development of retinopathy or nephropathy in diabetes patients.

\begin{tabular}{|l|l|l|l|l|}
\hline & Group-I & Group-II & Group-III & P value \\
\hline No & 54 & 30 & 152 & \\
\hline Sex (M/F) & $34 / 20$ & $5 / 25$ & $51 / 101$ & $0.0801 / 0.0004^{*} / 0.0000^{*} / 0.0029^{*} \#$ \\
\hline Age at study & $38.56 \pm 12.23$ & $49.47 \pm 9.97$ & $50.75 \pm 8.84$ & $<0.0001^{*} /<0.0001^{*} / 0.8342^{\star} /<0.001^{*} \#$ \\
\hline HbA1c & & $8.540 \pm 2.062$ & $8.694 \pm 2.238$ & 0.7786 \\
\hline Disease duration & & $7.516 \pm 5.067$ & $10.158 \pm 5.980$ & $0.0228^{*}$ \\
\hline
\end{tabular}

A Chi square test and ANOVA was used to calculate the differences. Values for continuous variables are given as mean \pm SD

* Statistically significant $\leq 0.05$, Significance levels refer to following group pairs: Group I vs. Group II/Group I vs. Group III/ Group II vs. Group III \#comparing the three groups

Table 1: Characteristics of individuals included in the study.

\begin{tabular}{|c|c|c|c|c|c|}
\hline \multirow{2}{*}{ Group } & \multicolumn{3}{|c|}{ Bg/ll polymorphism } & \multirow{2}{*}{ Total } & \multirow{2}{*}{ HWE } \\
\hline & $++\mathrm{n}(\%)$ & $+-\mathrm{n}(\%)$ & $--\mathrm{n}(\%)$ & & \\
\hline Group I (Healthy subjects) & $03(5.55)$ & $33(61.11)$ & $18(33.33)$ & 54 & 0.017128 \\
\hline Group II (Diabetic without retinopathy) & $4(13.3)$ & $16(53.3)$ & $10(33.33)$ & 30 & 0.542802 \\
\hline Group III (Diabetic with retinopathy) & $29(19.07)$ & $67(44.07)$ & $56(36.84)$ & 152 & 0.268781 \\
\hline Total & $36(15.25)$ & $116(49.15)$ & $84(35.59)$ & 236 & 0.695570 \\
\hline
\end{tabular}

Table 2: Frequency of Bglll polymorphism in Group I, Group II and Group III.

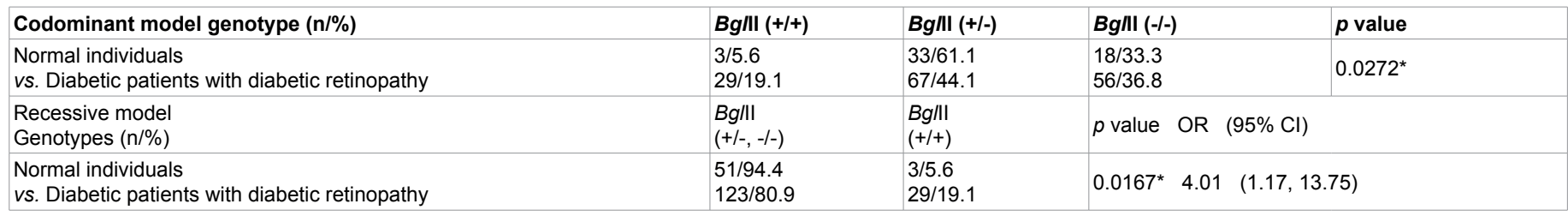

*Statistically significant $\leq 0.05$

Table 3: Association of Bg/ll genotypes with susceptibility to diabetic retinopathy.

\begin{tabular}{|c|c|c|c|c|}
\hline Bg/lI & $\begin{array}{l}\text { Normal individuals } \\
\text { Genotype }(\mathrm{n} / \%)\end{array}$ & Diabetic patients with diabetic retinopathy & $p$ value & OR $(95 \% \mathrm{Cl})$ \\
\hline $\begin{array}{l}+/- \\
+/+\end{array}$ & $\begin{array}{l}33 / 61.1 \\
3 / 5.6\end{array}$ & $\begin{array}{l}67 / 44.1 \\
29 / 19.1\end{array}$ & $0.0111^{*}$ & $4.76(1.35,16.78)$ \\
\hline $\begin{array}{l}-/- \\
+/+\end{array}$ & $\begin{array}{l}18 / 33.3 \\
3 / 5.6\end{array}$ & $\begin{array}{l}56 / 36.8 \\
29 / 19.1\end{array}$ & 0.1106 & $3.11(0.85,11.42)$ \\
\hline $\begin{array}{l}+/- \\
-/-\end{array}$ & $\begin{array}{l}33 / 61.1 \\
18 / 33.3\end{array}$ & $\begin{array}{l}67 / 44.1 \\
56 / 36.8\end{array}$ & 0.2411 & $1.53(0.78,3.01)$ \\
\hline
\end{tabular}

*Statistically significant $\leq 0.05$

Table 4: Effect of allele dose on association of Bg/ll genotypes with susceptibility to diabetic retinopathy. 


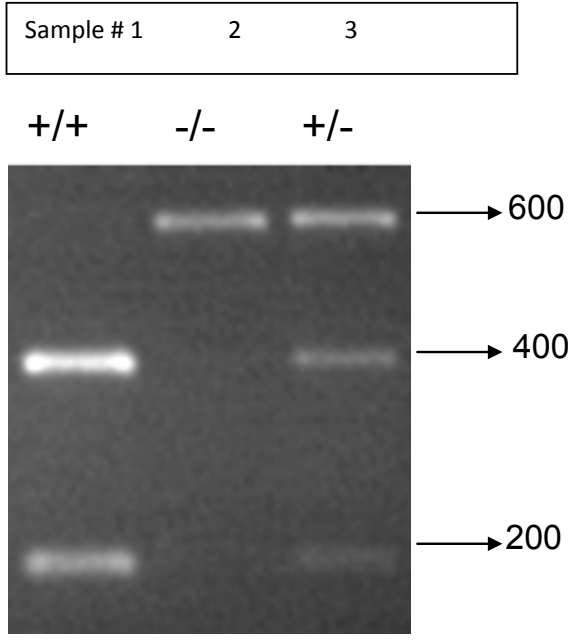

Sample 1: Homozygous for $B g l I I$ polymorphism Sample 2: Negative for $B g l$ II polymorphism Sample 3: Heterozygous for BglII polymorphism

Figure 1: Showing results of Bg/ll polymorphism

Prolonged hyperglycemia, alteration in retinal or renal blood flow, metabolic changes, hemostatic abnormality are associated with vascular dysfunction in microcirculation, which are thought to contribute in the occurrence or progression of DR and nephropathy. Platelets might be involved in the incidence of DR and nephropathy by altering retinal or renal blood flow that suggests the involvement of platelets in the pathogenesis of retinopathy in diabetes patient. The focus in the present study was on risk factors associated with retinopathy including age, duration of diseases and platelet adhesion, which is a critical step for primary thrombus formation and leads to intracellular activation processes. This study shows that the $B g l \mathrm{II}$ polymorphism is associated with the prevalence of retinopathy among patients with type II diabetes mellitus. The Bgl II $(++,+-)$ genotypes increased the risk of retinopathy. The $B g l$ II polymorphism has been reportedly associated with platelet $\alpha 2 \beta 1$ density, the extent of platelet adhesion to collagen, and the prevalence of myocardial infarction or stroke [6,22-30].

With reference to gender and age in retinopathy, present study is similar to another study reported from Pakistan by Jamal-u-Din et al. [27], who included $43.5 \%$ males and $56.5 \%$ females and by Tam et al. [31] who included 59.6\% females and 40.4\% males. Studies in Pakistan have shown impaired glucose tolerance as $6.3 \%$ in urban areas in men and $14.2 \%$ in women while in rural areas it is $6.9 \%$ in men and $10.9 \%$ in women [28]. However, national diabetic survey of Pakistan suggested higher prevalence of diabetes in males as compared to females while there is higher prevalence of impaired glucose tolerance in females as compared to males [25]. Nevertheless, Khan et al. [29] documented higher prevalence of diabetes in males (1.01\%) as compared to females $(0.76 \%)$ in certain districts of Pakistan. On comparison of age, there was significant difference among the three groups, between Group I and Group II and between Group I and Group III but Group II and Group III showed no significant difference (Table 1). The possible explanation for insignificant difference could be almost similar age range in Group II and Group III. Regarding age distribution, our results are same as reported by Chhutto et al. [30] where diabetic patients were between 15-65 years of age. The study of Ahmadani et al. [28] also support our study regarding mean age of the diabetic patients which was $49.9 \pm 10.8$. On comparison of percentage of HbAlc between Group II and Group III, there was no significant difference (Table 1). The reason for this non-significant value could be that in both the groups' distribution of HbAlc percentage was almost similar. The study of Ahmadani et al. [28] documented level of HbAlc as 9.32 \pm 2.14 and there was no significant difference in percentage of HbAlc. Tam et al. [31] documented percentage of HbAlc as $8.1 \pm 1.5$. On comparison of duration of diabetes between Group II and Group III, significant difference was found (Table 1). The possible explanation for this significance in duration of diabetes could be that along with other factors, length of disease could play a role in the development of DR. Regarding duration of diabetes, results of our study are similar with Ahmadani et al. [28] because they included patients of diabetes for $9.32 \pm 6.87$ years. Similarly, our study is in agreement with the study of Zhang et al. [32] as they included diabetic patients between 6.5-16.5 years.

This study is the first one to demonstrate an association between the $B g l$ II polymorphism and DR in Pakistani population. It is possible that BglII containing platelets can more easily interact with nonenzymatically glycosylated collagen and accelerate the occurrence of retinopathy. In addition, our findings might affect antiplatelet drug treatment for DR. For instance, patients with the BglII $(++$, $+-)$ genotype might benefit more from antiplatelet therapies. The frequency of BglII polymorphism (++, +-, and --) was determined in all the three groups (Table 2). The comparison among three groups was made by using codominant, dominant and recessive modes. By using co-dominant mode and recessive mode, comparison between Group I and Group III showed significant difference but comparison between Group II and Group III was not-significant (Table 3). The effect of allele dose was assessed for an association of BglII genotypes with the susceptibility to develop DR. There was significant difference on comparing +/- and +/+ between Group I and Group III. There was no significant difference on comparing $-/$ - with $+/+$, between Group I and Group III and on comparing +/- with -/- between Group I and Group III (Table 4). The percentage of HbAlc was compared with allele dose of BglII genotypes to determine the susceptibility to develop DR. On comparing all the variants $(+/+,+/-$, and $-/-)$ within Group II and Group III, there was no significant difference and $p$ value was 0.556 and 0.924 , respectively. Result of BglII polymorphism suggests that in our population $B g l I I$ polymorphism (++, and +-) genotypes play a significant role in the development of DR. The findings of our study are similar with the findings of Funatsu et al. [22] who were the first one to demonstrate an association between BglII polymorphism of a subunit of $\alpha 2 \beta 1$ integrin and DR among patients of T2DM in Japanese population. They suggested BglII $(+/+,+/-)$ genotypes increased the risk of retinopathy and nephropathy. Therefore, they suggested that patients with $B g l \mathrm{II}(+/-,+/+)$ genotypes might benefit from anti-platelet therapies. Similarly, Pavkovic et al. [19] studied polymorphism in GP Ia gene and suggested an association with the variations in platelet $\alpha 2 \beta 1$ expression levels. They suggested that platelets from individuals with $807 \mathrm{~T}$ allele have higher levels of $\alpha 2 \beta 1$ integrins as compared to individuals of $807 \mathrm{C}$ allele.

This study is also in agreement with the study of Petrovic et al. [18] who determined significantly higher frequency of $B g l I I(+/+)$ genotype of $\alpha 2 \beta 1$ integrin gene in patients of DR as compared to patients without DR. They suggested $B g l I I(+/+)$ genotype of $\alpha 2 \beta 1$ integrin gene polymorphism, age at the onset of diabetes, duration of diabetes, and insulin therapy as independent risk factors for the development of DR in Caucasians with T2DM. All the variables were compared among three groups and significant difference was observed between gender 
Citation: Afzal N, Nagi AH, Imran M, Zafar A, Musawar A, et al. (2012) Association of Alpha-2 Beta-1 Integrin Polymorphism with Retinopathy in Diabetic Patients. J Diabetes Metab 3: 223. doi:10.4172/2155-6156.1000223

distribution, age of subjects, and duration of diabetes. On comparison of Group I and Group II, significant difference was found between the ages of subjects (Table 1). On comparing Group I and Group III, significant difference was noticed between gender, age of subjects, and BglII gene polymorphism (Tables 1 and 3). On comparison between Group II and Group III, significant difference was found between gender of subjects, age, and duration of disease (Table 1). In conclusion, $B g l I I$ polymorphism of a subunit of $\alpha 2 \beta 1$ integrin is associated with the prevalence of retinopathy in patients with type II diabetes mellitus in Pakistani population. The present study may add in early identification of risk and possibly prevention of DR.

\section{Conclusion}

In the studied population, frequency of $B g l \mathrm{II}(+/+,+/-)$ genotype of gene polymorphism of $\alpha 2 \beta 1$ integrin gene, gender of subject, age at the onset of diabetes, and duration of diabetes contributed towards development of diabetic retinopathy.

\section{Acknowledgement}

We acknowledge Higher Education Commission Pakistan for the financial support, to University of Health sciences Lahore for providing equipment and other facilities and to the subjects who donated blood to carry out this study.

\section{References}

1. Cockram CS (2000) The epidemiology of diabetes mellitus in the Asia-Pacific region. Hong Kong Med J 6: 43-52.

2. Report of a WHO Consultation (1999) Definition, Diagnosis and Classification of Diabetes Mellitus and its Complications. WHO

3. Qidwai W, Ashfaq T (2010) Imminent epidemic of diabetes mellitus in Pakistan Issues and challenges for health care providers. JLUMHS 3: 112-113.

4. Danaei G, Friedman AB, Oza S, Murray CJ, Ezzati M (2009) Diabetes prevalence and diagnosis in US states: analysis of health surveys. Popul Health Metr 7: 16.

5. Wild S, Roglic G, Green A, Sicree R, King H (2004) Global prevalence of diabetes: estimates for the year 2000 and projections for 2030. Diabetes Care 27: 1047-1053.

6. Dedoussis GV, Kaliora AC, Panagiotakos DB (2007) Genes, Diet and Type 2 Diabetes Mellitus: A Review. Rev Diabet Stud 4: 13-24.

7. Singh R, Shaw J, Zimmet P (2004) Epidemiology of childhood type 2 diabetes in the developing world. Pediatr Diabetes 5: 154-168.

8. Chan JC, Malik V, Jia W, Kadowaki T, Yajnik CS, et al. (2009) Diabetes in Asia: Epidemiology, risk factors and pathophysiology. JAMA 301: 2129-2140.

9. Frank RN (2004) Diabetic retinopathy. N Engl J Med 350: 48-58.

10. Global Information Inc (2012) Insulin delivery devices - Increasing prevalence of diabetes to drive market.

11. Germer A, Biedermann B, Wolburg H, Schuck J, Grosche J, et al. (2004) Distribution of mitochondria within Muller cells--1. Correlation with retinal vascularization in different mammalian species. J Neurocytol 27: 329-345.

12. Wangsa-Wirawan ND, Linsenmeier RA (2003) Retinal oxygen: fundamental and clinical aspects. Arch Ophthalmol 121: 547-557.

13. Hakeem R, Fawwad A (2010) Diabetes in Pakistan: Epidemiology, Determinants and Prevention. Journal of Diabetology 3: 4.

14. Warpeha KM, Chakravarthy U (2003) Molecular genetics of microvascular disease in diabetic retinopathy. Eye (Lond) 17: 305-311.

15. Li H, Louey JW, Choy KW, Liu DT, Chan WM, et al. (2008) EDN1 Lys198Asn is associated with diabetic retinopathy in type 2 diabetes. Mol Vis 14: 1698-1704.

16. Uhlmann K, Kovacs P, Boettcher Y, Hammes HP, Paschke R (2006) Genetics of diabetic retinopathy. Exp Clin Endocrinol Diabetes 114: 275-294.

17. Jung SM, Moroi M (2000) Activation of the platelet collagen receptor integrin alpha(2)beta(1): Its mechanism and participation in the physiological functions of platelets. Trends Cardiovasc Med 10: 285-292.
18. Petrovic MG, Hawlina M, Peterlin B, Petrovic D (2003) Bgl11 gene polymorphism of the alpha2beta1 integrin gene is a risk factor for diabetic retinopathy in Caucasians with type 2 diabetes. J Hum Genet 48: 457-460.

19. Pavkovic M, Petlichkovski A, Stojanovic A, Trajkov D, Spiroski M (2010) Bgll polymorphism of the $\alpha 2 \beta 1$ integrin gene in Mecedonian population. Mecedonian Journal of Medical Sciences 3: 115-118.

20. Matsubara Y, Murata M, Maruyama T, Handa M, Yamagata N, et al. (2000) Association between diabetic retinopathy and genetic variations in alpha2beta integrin, a platelet receptor for collagen. Blood 95: 1560-1564.

21. Shi J, Gao W, Bai X, Wang Z, Ruan C (2001) Study of C807T polymorphism of the platelet collagen receptor alpha2 gene coding sequence in Suzhou Han population. Zhonghua Xue Ye Xue Za Zhi 22: 125-127.

22. Funatsu H, Yamashita H, Noma H, Mimura T, Nakamura S, et al. (2005) Aqueous humor levels of cytokines are related to vitreous levels and progression of Diabetic retinopathy in diabetic patients. Graefes Arch Clin Exp Ophthalmol 243: 3-8

23. Tsai DH, Jiang YD, Wu KD, Tai TY, Chuang LM (2001) Platelet Collagen receptor alpha2beta1 integrin and glycoprotein IIla $\mathrm{PI}(\mathrm{A} 1 / \mathrm{A} 2)$ polymorphisms are not associated with nephropathy in type 2 diabetes. Am J Kidney Dis 38 1185-1190.

24. Stevens FR, Hajeer A, John S, Thomson W, Worthington J, et al. (1999). The $\mathrm{Bg} / \mathrm{ll}$ polymorphism of the human prolactin gene lies within intron $\mathrm{C}$ and can be detected by PCR/RFLP. Eur J Immunogenet 26: 261-263.

25. Shera AS, Jawad F, Maqsood A (2007) Prevalence of diabetes in Pakistan. Diabetes Res Clin Pract 76: 219-222.

26. Nasiri H, Forouzandeh M, Rasaee MJ, Rahbarizadeh F (2005) Modified salting out method: high-yield, high-quality genomic DNA extraction from whole blood using laundry detergent. J Clin Lab Anal 19: 229-232.

27. Jamal-u-Din, Qureshi MB, Khan AJ, Khan MD, Ahmad K (2006) Prevalence of diabetic retinopathy among individuals screened positive for diabetes in five community-based eye camps in northern Karachi, Pakistan. J Ayub Med Coll Abbotabad 18: 40-43.

28. Ahmadani MY, Fawwad A, Basit A, Hydrie ZI (2008) Microalbuminuria Prevalence Study in Hypertensive Patients with Type 2 Diabetes in Pakistan. J Ayub Med Coll Abbottabad 20: 117-120.

29. Khan S, Abbas M, Habib F, Khattak IH, lqbal (2007) Prevalence of diabetes mellitus in Mirpur and Kotli districts of Azad Jammu \& Kashmir (AJ\&K). Sarhad J Agric 23: 1141-1143.

30. Chhutto MA, Qadar Habib-ur-R, Abro HA, Shaikh MA, Sheikh BA, et al. (2009) Awareness of diabetes mellitus and its complications in diabetic patients. Medical Channel 15: 153-156.

31. Tam VH, Lam EP, Chu BC, Tse KK, Fung LM (2009) Incidence and progression of diabetic retinopathy in Hong Kong Chinese with type 2 diabetes mellitus. $J$ Diabetes Complications 23: 185-193.

32. Zhang X, Saaddine JB, Chou CF, Cotch MF, Cheng YJ, et al. (2010) Prevalence of diabetic retinopathy in the United States, 2005-2008. JAMA 304: 649-656. 